\section{Questión}

Periodismo / Comunicación

ISSN 1669-6581

Epistemologías y saberes disidentes en la Universidad

María Cecilia Johnson, Paola Bonavitta

Question/Cuestión, Vol. 2, N66, Agosto 2020

ISSNe 1669-6581

https://perio.unlp.edu.ar/ojs/index.php/question/index

IICom-FPyCS-UNLP

DOI: https//doi.org/10.24215/16696581e489

\title{
Epistemologías y saberes disidentes en la Universidad
}

\section{Dissident epistemologies and knowledge at the University}

María Cecilia Johnson

Centro de investigaciones y Estudios sobre Cultura y Sociedad, Universidad Nacional de Córdoba, Consejo Nacional de Investigaciones Científicas y Técnicas, Argentina cecilia.johnson@unc.edu.ar https://orcid.org/0000-0002-5102-2504

Paola Bonavitta

paola.bonavitta@gmail.com

https://orcid.org/0000-0003-4758-4202

Centro de Investigaciones de la Facultad de Filosofía y Humanidades, Universidad Nacional de Córdoba, Consejo Nacional de Investigaciones Científicas y Técnicas, Argentina 


\section{Resumen}

Este trabajo presenta avances de un proyecto de investigación marco que realizamos desde la Universidad Nacional de Córdoba en el contexto de la Red de Investigación en diferenciales de género en la Educación Superior Iberoamericana de la Universidad de Alicante. El proyecto marco se centra en las desigualdades de género en las diferentes carreras universitarias.

En este artículo indagamos sobre las universidades que habitamos y las relaciones de poder que allí se manifiestan, situándonos en la Universidad Nacional de Córdoba. Asimismo, reflexionamos sobre otras maneras de generar saberes y de compartirlos en el contexto institucional, con la intención de construir y sostener una Universidad que dispute sentidos a los saberes hegemónicos androcéntricos, patriarcales, binarios y coloniales.

Utilizamos tanto la metodología cuantitativa como la cualitativa, recurriendo a técnicas de ambas: encuestas y entrevistas focalizadas en profundidad. Trabajamos con estudiantes y egresados recientes (no más de cinco años de haber finalizado su cursado) y, puntualmente, con estudiantes y egresados pertenecientes LGTTTBQI+.

La intención es conocer qué saberes son los que circulan hegemónicamente dentro de la universidad pero también aquellos que, marginalmente, gestan otras maneras de ser y estar en el contexto educativo.

\section{Palabras Clave}

Educación universitaria; feminismos; disidencias; saberes; hegemonía 


\section{Abstract}

This work is the result of a framework research project that we carried out from the National University of Córdoba in the context of the Research Network on gender differentials in Ibero-American Sup Education from the University of Alicante. The framework project focuses on gender inequalities within the different university careers.

In this article we inquire about the universities we inhabit and the power relations that are manifested, departing from the National University of Cordoba's experience. Likewise, we reflect on other ways of generating knowledge and sharing it in the institutional context, with the intention of building and sustaining a University that disputes the hegemonic androcentric, patriarchal, binary and colonial knowledge.

We use both quantitative and qualitative methodology, using both techniques: in-depth focused surveys and interviews. We work with recent students and graduates (no more than five years after completing their course) and, punctually, with students and graduates belonging to LGTTTBQI +.

The intention is to know what knowledge is the one that circulates hegemonically within the university but also that which, marginally, create other ways of being and being in the educational context.

\section{Key Words}

University education; feminisms; dissidences; knowledges; hegemony

\section{Introducción y Fundamentación:}

Las universidades en general, como espacios de reproducción del saber-poder dominante, de alguna manera perpetúan el clasismo, sexismo y racismo de 
nuestras sociedades latinoamericanas. Son, asimismo, espacios patriarcales de poder, donde el saber legitimado es aquel que es producido por varones blancos, quienes son, además, los sujetos que dirigen estas casas de estudio en Nuestra América.

Las universidades, al igual que otros ámbitos educativos y laborales, no están exentas de alojar cualquier tipo de conducta violenta con motivaciones sexuales y de género como el abuso sexual, la discriminación o el acoso sexual, basados en el poder desigual que atraviesa todas las relaciones interpersonales y generando desventajas específicas para las mujeres y otras personas con identidades sexuales disidentes de la heteronormada" (Rovetto y Figueroa, 2017, p. 2).

Amelia Valcárcel (2008) asegura que vivimos en el "espejismo de la igualdad", es decir que hombres y mujeres creen que somos iguales y que, por tanto, ya no habría de qué preocuparse. Para la autora, se trata de una apariencia pero no de lo que sucede efectivamente puesto que no han accedido a puestos de poder en espacios "como el financiero-empresarial, el de los medios de comunicación, el académico y del saber, en la creatividad y en el religioso" (Valcárcel, 2008).

En el ámbito educativo, la situación de las mujeres ha cambiado considerablemente con los años; no obstante, perduran la feminización de las carreras de cuidado así como la no representatividad femenina en los puestos de poder y jerárquicos. Además, la educación y sus instituciones continúa sosteniendo un sesgo positivista y aún colonialista. Para Viveros Vigoya (2009), el racismo y el sexismo de los enfoques científicos dominantes, naturalizan la diferencia y la desigualdad social, argumentando que las relaciones sociales son biológicas y basadas en las diferencias fenotípicas (como el color de piel). 
A su vez, ambos asocian el dato corporal con la realidad social y caracterizan a los grupos que no son dominantes como predispuestos a la sumisión. Asimismo, crean supuestos universales acerca de las experiencias de los/as subalternos, como la utilización de la categoría mujer sobre mujeres, para ocultar las diversas experiencias y modos culturales de experimentar el género, la clase, etcétera (Bard Wigdor y Artazo, 2016).

Tal como sostiene la OIT (2016): "En la práctica, la educación sigue siendo una institución social que refleja y reproduce las desventajas socioeconómicas y culturales prevalecientes en el resto de la sociedad" (p.1). Sin embargo, consideramos que en los distintos niveles del sistema educativo -incluido el superior- conviven naturalizaciones, divisiones jerarquizantes y políticas disciplinarias de género con búsquedas a contrapelo, en un sentido liberador e igualador.

Escribimos desde la Universidad Nacional de Córdoba (UNC), en el centro de Argentina; una institución de origen jesuita ubicada en la ciudad de Córdoba, la cual es denominada "la Docta" justamente por la temprana creación de la Universidad en la ciudad y el prestigio académico que ésta poseía. Como muchos espacios del saber latinoamericanos, la UNC conserva sexismos, racismos, clasismos en sus programas de estudio, en sus prácticas y en el ejercicio de docentes y autoridades.

No obstante, también ha generado espacios de resistencia a prácticas no inclusivas o no democráticas, permitiendo rupturas con las normas dominantes. Para citar algunos de estos, podemos nombrar que la Universidad Nacional de Córdoba es una institución pionera en el reconocimiento de derechos de la ciudadanía universitaria, donde se reconoce desde 2011 el derecho a la identidad autopercibida de las personas ${ }^{1}$, previamente a la sanción de Ley de 
Identidad de Género (2013) en Argentina. Asimismo existen procesos de construcción y resistencia desde otros espacios, docentes, estudiantiles, no docentes, dentro, fuera y en los márgenes de las aulas. Y es en este punto en el que enfocaremos en este trabajo, pues aquí apuntamos a reflexionar sobre aquellos puntos de fuga que permiten pensar en espacios más amigables, inclusivos y populares en el acceso y la permanencia de la institución.

Este trabajo presenta avances de una investigación marco que realizamos entre investigadoras de la UNC y de la Red de Investigación en diferenciales de género en la Educación Superior Iberoamericana de la Universidad de Alicante. En el mismo, hemos utilizado técnicas cuantitativas y cualitativas para recoger los datos y poder complejizar la mirada sobre las condiciones en las que se dan los procesos educativos.

\section{¿Son posibles las pedagogías no heteronormadas, ni binarias e interseccionales?}

La universidad constituye un espacio de disputa de sentidos y de poderes. Como toda institución educativa, construye sentidos, saberes y representaciones del mundo. Lo que se reflexiona y significa en estos espacios, terminan generando cosmovisiones e ideas, visibilizan o contribuyen a ocultar problemáticas sociales. Por tanto, es un espacio de poder. $\mathrm{Y}$, como tal, debemos indagar sobre las relaciones que allí se construyen y generan de acuerdo a lo que hace al contenido de la enseñanza, los saberes válidos y "lo transmisible" en el marco del aula e incluso fuera de ellas.

Irene Martínez (2018), por su parte, señala que la educación no es neutral y se encarga de reproducir sociedades desiguales, al asociar lo masculino al poder y la superioridad intelectual o física, y lo femenino a la sumisión y dependencia. 
Reproducir esos micromachismos, fomenta las violencias de género. Desarmarlos, repercute en la construcción de una sociedad más justa, igualitaria y equitativa.

En una sociedad patriarcal, capitalista, sexista y colonial, las instituciones educativas continúan promoviendo una identidad heteronormada y androcéntrica. No hay lugar para las diversidades ni para pensar/crear el mundo fuera de las normas sostenidas por el cisheteropatriarcado. Nos preguntamos por qué la escuela y las instituciones educativas promueven una cultura institucional heteronomativa y reflexionamos junto a Val Flores, quien habla de la política de la ignorancia como política:

"En el campo de la educación, la ignorancia siempre fue considerada como lo opuesto del conocimiento y, por consiguiente, repudiada. Sin embargo, algunas teóricas queer que se dedicaron a indagar y desarmar el binomio conocimiento/ignorancia, en relación con la heterosexualidad/homosexualidad -pares que articularon buena parte del discurso científico moderno-, comenzaron a entender la ignorancia como implicada en el propio conocimiento" (Flores, 2008, p.18).

Tal como señala Flores (2018), en el proceso histórico de creación de la heterosexualidad/homosexualidad, en el siglo XIX, 'conocimiento' significaba, en primer lugar, conocimiento de la sexualidad "normal" e ignorancia de las sexualidades "desviadas", "anormales", "perversas". De este modo, conocimiento y sexo se volvieron conceptualmente inseparables uno del otro. El conocimiento de nuestro cuerpo y el cuerpo de conocimientos se convierten, entonces, en un escenario de normalización. A este conocimiento (la heterosexualidad) que produce des-conocimiento (sexualidades disidentes), Britzman le llamará "pasión por la ignorancia", o casos de normalidad 
exorbitante. Esta pasión por la ignorancia se relaciona con la represión, con olvidar una idea, con separar la idea del afecto (Flores, 2008): "Expresiones como: "yo no sé nada de eso", "eso no tiene nada que ver conmigo", sustentan la labor de la ignorancia" (Flores, 2008, p.18).

Rich (2001), por su parte, sostiene que en las instituciones educativas a través de las prácticas educativas, los contenidos de los planes de estudio, la estructura institucional, la lengua y la cultura en su conjunto, se ha marcado la existencia de las mujeres y sujetos feminizados ${ }^{2}$ bajo el signo de la exclusión, la inadecuación, la diferencia, ubicándolas en el lugar de objeto y anulando su capacidad para asumir retos, formular preguntas, atreverse a pensar. Los contextos académicos y científicos son androcéntricos. Frente a ello, apelar a la condición de las mujeres como seres pensantes, o como proponía esta autora, - pensar como mujer-, no significa necesariamente reclamar la sustitución de un pensamiento sesgado por otro ni reforzar dualidades genéricas, que pudieran ser complementarias, sino, como plantea Diana Maffía (2007), tratar de cuestionar la dualidad jerarquizada en que se sostiene la marca invisible de la ciencia, entendida como proceso, en el seno de una comunidad, y como producto o conocimiento (Bonilla Campos, 2014).

Es por ello que, considerando lo antes dicho, debemos proponernos pensar en pedagogías feministas interseccionales que se atrevan a romper las normas dominantes y a contemplar las diversas posibilidades de ser de los y las sujetos/as que acceden a la educación universitaria.

"Los debates pedagógicos feministas se han desarrollado en diálogo con las pedagogías críticas, coincidiendo ambas en pensarse como pedagogías liberadoras y revolucionarias. Este último aspecto es un elemento atendible desde el punto de vista de las exigencias del movimiento feminista estudiantil, 
al señalar la necesidad de comprender un espacio y "pedagogía otra" que pueda fomentar un proceso de libertad, más que de desigualdad y discriminación. Cuando las estudiantes señalan el carácter "patriarcal del sistema educativo", dan cuenta de los amarres y conflictos que se gestan en su interior, donde el feminismo se yergue como una posibilidad de transformación efectiva. Por ello es pertinente atender las propuestas que las pedagogías liberadoras han planteado al respecto" (Lelya Troncoso Pérez, Luna Follegati, Valentina Stutzin, 2019, p. 6)

Atender a la interseccionalidad en materia educativa se vuelve absolutamente necesario sobre todo en el contexto latinoamericano, el más desigual del mundo. Para ello debemos pensar en las intersecciones de género, raza, clase, origen, etnia, orientación sexual, entre otras; pues ello determinará las diferencias en los accesos y las posibilidades de acceder y permanecer en los espacios educativos superiores.

\section{Metodología de trabajo}

Como señalamos, este trabajo es parte de una investigación marco que realizamos desde hace tres años sobre educación superior y desigualdades de género. La misma se lleva adelante en la UNC en el marco de la Red de Investigación en diferenciales de género en la Educación Superior Iberoamericana de la Universidad de Alicante y ha ido indagando en los planes de estudio de las carreras que conforman a la Universidad así como también en las prácticas que se sostienen en la institución entre estudiantes, docentes y no docentes.

Este artículo reúne reflexiones surgidas a partir de un trabajo de campo extenso con estudiantes y egresados/as recientes (no más de cinco años) de la 
UNC. Hemos recurrido a técnicas de investigación cuantitativa y cualitativa. La información recolectada fue utilizada de insumo para la redacción de este trabajo, no obstante no fue presentada en su totalidad por cuestión de espacio y de selección temática.

En primer lugar, indagamos, a partir de entrevistas focalizadas, las prácticas educativas más corrientes de la UNC. Se entrevistó a estudiantes LGTTTBQI+ para que pudieran dar cuenta de su tránsito por la universidad y si se han sentido o no representadas/os en la misma. La intención fue reconocer si las prácticas universitarias son inclusivas, no binarias, no sexistas e interseccionales. En segundo lugar, aplicamos un cuestionario virtual a partir de un muestreo anónimo y no probabilístico. Respondieron al mismo mujeres, varones y personas LGTTTBQI+ (estudiantes en curso o que hayan egresado en un período menor a cinco años) que nos sirvió para reconocer las demandas del estudiantado en relación con la perspectiva feminista y no binaria y la inclusión activa de sujetos no hegemónicos en las prácticas universitaria.

Para reflexionar sobre las prácticas educativas disruptivas con la norma que propone la UNC, tomamos los relatos de estudiantes y egresados LGTTTBQI+. Finalmente, buscamos explorar sobre propuestas que desafíen a la educación heterocispatriarcal tradicional y que convivan y alienten otras formas de educar, sostenidas en las prácticas feministas, interseccionales y no binarias.

Recoger los discursos de quienes protagonizan los procesos educativos nos pareció de suma importancia, puesto que, como feministas latinoamericanas, apostamos a un saber situado y a recuperar las voces de quienes efectivamente atraviesan por las situaciones de las cuales hablamos. 


\section{Algunos ejes para pensar las relaciones saber-poder en la UNC}

A través de entrevistas y encuestas realizadas a estudiantes de diferentes facultades durante el período 2017-2019, se pudieron advertir algunos aspectos que dan cuenta de atravesamientos patriarcales que en ocasiones están a la vista y en otras, se encuentran invisibilizados.

Retomando las voces críticas sobre la UNC que se desprenden de esta investigación, proponemos tres superficies (Ahmed, 2015) entendidas como coordenadas en el espacio universitario, mediante las cuales intentamos graficar las maneras en que el poder circula y los efectos que tiene sobre los cuerpos generando desigualdades.

Como señala Teresa De Lauretis (1996) "como la sexualidad, el género no es una propiedad de los cuerpos o algo originalmente existente en los seres humanos, sino el conjunto de efectos producidos en los cuerpos, los comportamientos y las relaciones sociales, en palabras de Foucault, por el despliegue de una tecnología política compleja" (De Lauretis, 1996, p. 9).

Entendemos que poder descifrar las relaciones de poder que se traducen en desigualdades de género, nos permite señalar las formas de resistencia, las pedagogías feministas, los saberes que surgen al calor de la militancia y el activismo, en las rebeldías sostenidas por docentes, estudiantes y actores que disputan estos espacios aunque sea desde los márgenes. Para ordenar lo indagado, dividimos en tres subapartados la información: a) Sobre la superficie; b) Discursos que circulan en los márgenes; y c) Le/as/os invisibles.

a) Sobre la superficie 
En la superficie podemos advertir las maneras en que ciertas violencias se expresan en el espacio universitario. Siguiendo a Sara Ahmed entendemos que:

"Los cuerpos adoptan las formas de las normas que se repiten como fuerza a lo largo del tiempo. La labor de repetición supone ocultar el trabajo bajo el signo de la naturaleza (...) las normas aparecen como las superficies de los cuerpos" (Ahmed, 2015, p. 222).

Asimismo, la autora entiende que "la heterosexualidad obligatoria moldea los cuerpos al suponer que "tiene que" orientarse hacia algunos objetos y no otros, objetos que están afianzados como ideales mediante la fantasía de la diferencia" (Ahmed, 2015, p. 223).

En primer lugar, las encuestas señalan formas de violencia expresiva atravesando las relaciones entre docentes-estudiantes, pero desigualmente distribuidas. Nos referimos a las violencias expresivas a las que Rita Segato (2008) hace referencia cuando sostiene que funcionan como un acto discursivo, una firma de soberanía y apropiación sobre los cuerpos feminizados.

Existe una percepción, de parte de las personas participantes de este estudio, de que se ejerce una particular forma de violencia de género sobre los cuerpos feminizados: actitudes homo, lesbo y transodiantes desde las formas más explicitas a las más invisibilizadas.

Específicamente, las y los estudiantes reconocen prácticas de enseñanza de la profesión donde se ejercen violencias de todo tipo que se expresan también en las formas de enseñanza-aprendizaje:

Estoy pensando por ejemplo, en la cátedra de ginecología que fue donde más pudimos abordar salud sexual y reproductiva digamos, como un aspecto 
importante dentro de la formación en políticas de género y diversidad, pero al mismo tiempo es una de las cátedras más violenta en el tratamiento con las mujeres pacientes, que uno tiene contacto también con ellos, digamos (C., Medicina).

La estructura misma de las cátedras universitarias, con sus jerarquías, dificulta las transformaciones en la producción del saber y en los procesos de enseñanza-aprendizaje; así como también revela formas naturalizadas de violencias entre docentes:

Mi facultad tiene un funcionamiento en donde las cátedras se constituyen como una especie de feudos muy desarticuladas una de las otras, en donde los docentes forman parte del cargo hace muchísimos años, entonces los direccionamiento que cada cátedra terminan teniendo o poniendo en lo académico limita mucho, porque en general se constituye con sujetos muy conservadores, que lejos están de poder tratar esas temáticas (C., Medicina)

En segundo lugar, entendemos que las disposiciones áulicas también manifiestan formas coloniales del saber-poder y detentan, asimismo, microviolencias. Este aspecto -que es cuestionado duramente por la pedagogía crítica y que se reproduce en las expresiones del estudiantado en esta investigación- se vincula con el ordenamiento físico del aula. Por ejemplo, la disposición de los asientos y de la pizarra, ordena visual y espacialmente a quien, se supone, porta el saber y a quienes están allí para receptarlo. Esta lógica espacial verticalista fue criticada por la mitad de las personas encuestadas como un aspecto a transformar.

En tercer lugar, la heteronorma se manifiesta en las superficies también en la manera en la que los espacios físicos de la universidad y su diseño 
arquitectónico-habitacional son generizados de forma binaria, como sucede con los baños de la universidad. Sobre este aspecto Ahmed (2015) señala que:

"La heteronormatividad funciona como una forma de confort público al permitir que los cuerpos se extiendan a espacios que ya adoptaron su forma. Esos espacios se viven como espacios cómodos en la medida que permiten que esos cuerpos encajen. (...) . Como ha sostenido Gill Valentaine, la "hetrosexualización" de espacios públicos como las calles, se naturaliza debido a la repetición de diferentes formas de conducta heterosexual (imágenes en anuncios espectaculares, la música que se toca, demostraciones de intimidad heterosexual y demás) un proceso del que no se percatan los sujetos hetersexuales". (Ahmed, 2015, p. 226)

Un aspecto que se plantea por parte de las personas trans es la necesidad de plantear resoluciones basadas en su propia experiencia en estos espacios. La sola creación de un baño sin género no garantiza la seguridad de las personas trans, quienes plantean que temen entrar al baño socialmente reconocido como "de varones". De esta manera, estas experiencias parecieran invisibilizadas en las mismas respuestas institucionales.

Cuando las miradas comienzan a ampliarse, se da la posibilidad institucional de existir de múltiples maneras y evitar los binarismos dañinos y excluyentes. Algunas facultades han implementado los baños por fuera de la norma, sin adherir al sistema sexo-género. Esto permite que todas las personas puedan sentirse parte y facilita la apropiación y circulación por los espacios que solían ser expulsivos.

Lo que aparece como una estrategia interesante que surge desde la propia vivencia, es el uso de de los baños con una lógica que les proteja: 
“(...) nos pasa que no tenemos ganas de entrar a un baño con varones cis porque tenemos miedo, entonces dijimos bueno, un baño va a ser sin género y el otro baño es para cualquier persona menos varones cis". (L., trans, UNC). Cuando pensamos en una institución educativa que abarque a todas las personas, debemos considerar este tipo de cuestiones que involucran a lo espacial-habitacional. Para ello, la mirada feminista, no binaria, interseccional es fundamental.

b) Discursos que circulan en los márgenes

Aquí nos referimos a los saberes y discursos que circulan en el espacio universitario, en sus aulas y fuera de ellas. Es la performatividad del discurso, que no es mera palabra, sino que se entiende como un discurso que opera y tiene efectos en la construcción de realidad.

El discurso que circula es aquel que tiene poder. Delimita las fronteras entre quienes enseñan y quienes aprenden, demarca las fronteras entre quiénes son "sujetos" y quiénes son "objetos" de conocimiento. Sin embargo, siguiendo a De Lauretis, intentaremos recuperar aquello que aparece en los márgenes del discurso hegemónico, intentaremos reconstruir cómo circulan y de qué manera otras corporalidades, otras formas de habitar la UNC desde las microresistencias:

"...espacios sociales cavados en los intersticios de las instituciones y en las grietas y resquebrajaduras de los aparatos del poder-saber. $\mathrm{Y}$ es allí donde pueden formularse los términos de una diferente construcción de género, términos que sí tengan efecto y se afiancen en el nivel de la subjetividad y de la autorepresentación: en las prácticas micropolíticas de la vida de todos los días $y$ en las resistencias cotidianas proporcionan tanto la agencia como los recursos de poder o de habilitar investiduras; $y$ en las producciones culturales 
de las mujeres feministas, que inscriben ese movimiento dentro y fuera de la ideología, que cruzan de atrás para adelante los límites -y las limitaciones- de la(s) diferencia(s) sexual(es)" (De Lauretis, 1996, p. 33).

Este aspecto se vincula directamente con las disputas epistemológicas, encontrando experiencias que cuestionan el dictado la ausencia de teorías feministas y LGBTTTQI+, hasta la inclusión de las teorías feministas sólo de forma marginal en algún seminario específico, que no es acreditado por la currícula.

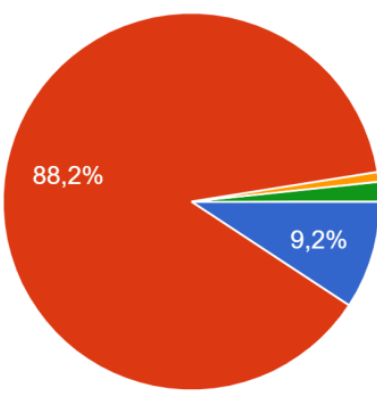

Figura 1: ¿Es relevante la inclusión de autores LGBTTTIQ+ y no binaries? Fuente: Elaboración Propia.

Como señalan algunos/as estudiantes, es posible encontrar algunas experiencias en los espacios educativos que favorecen la circulación y expresión de otros saberes, pero de forma subalterna. Mediante en un circuito diferenciado, surgen cursos, talleres, seminarios opcionales, docentes y bibliografía que facilitan acercamiento y profundización de teorías feministas y 
no binarias. Son espacios minoritarios y muchas veces marginales, pero están ahí y permiten correr la mirada ante tanto androcentrismo.

No obstante estas excepciones, lo dominante siguen siendo las teorías, cátedras, prácticas docentes y bibliografías marcados por la lógica patriarcalcapitalista-colonial céntrica. En primer lugar se advierte una jerarquía donde las perspectivas biologicistas priman sobre otros saberes a la hora de abordar el cuerpo y las identidades:

“(...) medicina tiene una perspectiva de formación casi estrictamente biologicista que limita mucho poder discutir estas otras cuestiones que atraviesan a la salud. Si hay, de todas formas, materias que se suponen que tienen que introducirnos en el campo de las ciencias sociales también, pero son materias que en general son ninguneadas y que no terminamos dándole importancia a esas materias, pero porque la estructura misma no nos permite eso". (Estudiante, no binaria, UNC)

Partiendo de lo que supone incorporar la perspectiva de género de forma transversal, las teorías feministas si aparecen, lo hacen de forma marginal, como una última unidad, como un contenido secundario, en lugar de constituir una mirada desde donde repreguntar, cuestionar los saberes establecidos (Rodigou Nocetti en Oliva, 2018).

"[La perspectiva de género en Derecho]... por ahí en esa facultad tendría que ser transversal a todas las materias. Yo me acuerdo que en una materia, que es historia del derecho, hay una bolilla que es historia de las mujeres, que después nunca se daba en historia. O ponele, se me ocurre en privado, uno que es derecho civil, donde las mujeres éramos incapaces y después de un tiempo, todo eso se podría ver con perspectiva de género, se podría analizar en el derecho penal también, los casos de aborto, después también el adulterio 
que estaba penado para las mujeres y no para el varón, en todas las materias pero desde una forma transversal. O sea, en sociología, en filosofía, que te toca un profe piola, porque tampoco es que en todas esas materias tiene garantizada la perspectiva de género, o sea no, si te tocaba un profe piola capaz que ahí lo veías" (Estudiante, lesbiana, Derecho).

Una consecuencia de no transversalizar tiene un efecto de construcción de una realidad heteronormada, como señala una estudiante:

"En la materia Adolescencia se daba algo en la última unidad, la cual no se preguntaba nunca, sobre familias homoparentales, sin que haya salido todavía la ley de adopción, pero desde una mirada también psicoanalítica. La facultad de Psicología está muy atravesada por el psicoanálisis que es bastante patriarcal digamos. Sólo ahí a lo último aparecía para decir está y nada más" (Estudiante, UNC).

En el dictado de las materias en ocasiones se incorporan algunos textos feministas. No obstante, se continúa invisibilizando a las personas y los saberes trans. En las encuestas, el 92\% afirmó que no habían leído a personas trans en su carrera y que tampoco habían tenido docentes trans. Por tanto, más allá de que se ofrezca bibliografía con perspectiva de género, son personas cisgénero las que hablan por las personas trans.

"En geografía no, de hecho personas trans no tenemos nada, ni siquiera hay una referencia a alguien trans en mi carrera. Autoras mujeres cis leímos muy pocas, la mayoría se ven en materia optativas. En nuestra carrera tenemos un porcentaje de materias para cursar que son optativas y dentro de esas optativas si hay algunas materias que tenemos autoras mujeres cis, pero son muy pocas digamos, con una perspectiva como más de género o feminista no, hay muy poco análisis" (Estudiante, trans, UNC). 
Como vemos, cuando aparece en la currícula la teoría feminista, lo hace desde una perspectiva binaria y, además, transmitida por docentes cisgénero. Es así que lo que legitima a la "transmisión" del conocimiento es una posición cis que legitima al saber y al poder.

"En las carreras de sociología y ciencias políticas, en ciertas materias, como Teoría Sociológica, hemos visto textos con temáticas de género y disidencias, más particularmente en cuanto a feminismo digamos, que en disidencias en general. Hemos visto "El segundo sexo de Simone de Beauvoir", y varias otras autoras feministas puntualmente. En sí textos de disidencias sexuales donde se hable de las diferentes disidencias y demás no he leído en el marco de ninguna materia. Sí en este año, hay una oferta en Antropología Sociocultural, que tiene en una parte de su programa, la teoría queer. (M., marica, Ciencias Sociales)

"Me parece un despropósito hablando de cuestiones trans, cuando el 1\% de personas trans estudian en la universidad, todavía no sé si tiene sentido, sé que es necesario producir material desde ahí porque las producciones que hay sobre cuestiones trans son por personas cis que generalmente pecan de un montón de cosas porque nada, no leen autores trans por ejemplo (...), hay un montón de personas trans escribiendo pero no nos leen por algún motivo y siempre están escribiendo desde que es lo que dicen las personas cis de nosotres, y nada, no dicen cosas tan interesantes como decimos nosotres que nos pasan por el cuerpo, porque que te citen a Butler en lugar de un autor trans (...) Butler se queda muy corta y hay un montón de críticas de los estudios trans a Butler, y como que les cuesta salir de ahí o salir de este hilo, esta 
fascinación por la marginalidad y nada, de leer siempre la excepcionalidad" (A. varón trans).

También algunas entrevistas son críticas de algunos programas institucionales por no recuperar la experiencia de las propias personas involucradas: "Se generan pequeños programitas universitarios que tienen que ver con la inclusión pero realmente no es inclusivo porque ¿cómo podés pensar algo por otras personas si ni siquiera la oíste?" (N., trans).

Como señalan en las entrevistas, la Universidad no siempre habilita voces disidentes. Existe una percepción desde el estudiantado que, si lo hace, es desde espacios marginales, periféricos. Sin embargo algunos de estos espacios se han ido institucionalizando a lo largo de los años, como espacios de formación y resistencia.

En las respuestas de las encuestas se propone que se incluyan nuevos formatos pedagógicos, que si bien valoran el dispositivo de los artículos científicos, también se propone la incorporación de imágenes, videos, música, fanzines y poesías como nuevos lenguajes que permitan la construcción de un conocimiento no unidireccional. También surge de las encuestas, la posibilidad de que se inviten a personas y colectivos LGBTTTQI+ a participar de los espacios académicos, para que nadie sea su portavoz y que puedan efectivamente estar representados allí. Ello democratizaría la palabra y permitiría apostar a otras modalidades y formas de aprender y enseñar en la UNC.

Otras voces que circulan en los márgenes tienen que ver con aquellos conocimientos y discursos que cuestionan la colonialidad del poder.

El perfil profesional que se construye en los espacios académicos responden al saber-poder dominante y colonial, que se concentra en la figura del varón 
blanco, burgués y eurocentrado. Como señalan algunas estudiantes: "Me dí cuenta de que, cuando terminé la Universidad, pensaba como un varón europeo y blanco, no había leído nada autoras y menos latinoamericanas" (Estudiante, artes, UNC). Bibliografías obligatorias, vínculos establecidos con las y los estudiantes, la organización espacial del aula que favorece una demarcación jerárquica, todo ello potencia la formación de profesionales androcéntricos y heteronormados. Se repiten saberes y estructuras coloniales de aprendizaje y transmisión de los saberes.

Frente a las herramientas que se obtuvieron en las encuestas para mejorar la o favorecer el dictado de clases no binaria e inclusiva, se encontraron algunas propuestas por parte de los y las estudiantes encabezadas por las ampliación de la bibliografía obligatoria. Esto nos lleva a preguntarnos ¿a quiénes leemos en las universidades? ¿Quiénes son nuestros referentes teóricos? Y esto mismo, claramente, nos lleva a plantearnos el androcentrismo en la ciencia y en la educación.

c) Le/as/os invisibles

Otra superficie que es preciso señalar en la UNC es la invisibilización de las identidades y asunción de una heteronorma en la Universidad en los discursos, en las relaciones de enseñanza-aprendizaje.

La manera de nombrar a las y los estudiantes refiere a un uso permanente del supuesto universal masculino por parte del cuerpo docente. Esto no sólo invisibiliza a las mujeres presentes en las clases sino también a las personas LGTTTBQI+. La política de desconocimiento e invisibilización de las sexualidades disidentes, se hace visible en los discursos de docentes no sólo en lo que respecta a la currícula, sino en lo que habita como "sentido común" en los pasillos, en el "chiste", en los ejemplos, en las demostraciones afectivas 
posibles que se asumen y normativizan como heterosexuales. Así surge de las entrevistas una estudiante autoidentificada como lesbiana señala "yo pude ser, pero en los márgenes de la facultad. En las aulas, en los pasillos, en toda esa estructura, y en toda esa formalidad que tienen esa facultad no, no estaba permitido, no estaba permitido hablar de una novia"

De la misma manera el $72,3 \%$ de las personas encuestadas señaló que lo que es preciso modificar las formas de nombrarnos en la UNC, que desconocen las identidades de las personas que habitan la institución. Estas formas reproducen un modelo heteronormativo, que en lo cotidiano se reproduce en las conversaciones y en el sentido común. Así señalaba una estudiante: "en la mayoría de las clases los chistes eran de las relaciones heterosexuales siempre, -"¿usted tiene novios?, o -"dígale a su novio"- eso siempre, siempre, eso entre los compañeros, entre docentes" (Estudiante, lesbiana, UNC). Ya sea desde la omisión, como desde el silencio, estamos hablando de formas de violencia institucional contra los actores universitarios que no se ajustan a la heteronorma. Como señala una persona encuestada, ello tiene efectos negativos en la formación del estudiantado:

Somos sujet*s que disputamos la producción de ausencias que históricamente se ha realizando contra nuestras corporalidades, subjetividades, deseos. (...) Si hay corporalidades y experiencias que no se enuncian, no se inscriben en un imaginario de lo posible o lo deseable, hay una parte de lo real que no estamos representando. Una formación no-incluyente no sólo tiene consecuencias en el perfil profesional que la academia promueve, sino que se constituye como una práctica de violencia institucional homolesbotrans/odiante. ¿Lo que no se nombra no existe? Aún peor. Existimos, resistimos y en muchas oportunidades padecemos de esos silencios. (Estudiante de Posgrado, UNC) 
Un aspecto que apareció de forma crítica en las entrevistas, se vincula a la invisibilización que existe sobre estudiantes trans y no binarios, como la población estudiantil que encuentra mayores obstáculos para sostener el tránsito para la universidad, que termina siendo expulsiva. Esta invisibilización se manifiesta en la manera en que se asume de antemano de que todas las personas son cis género: "eso es un problema digamos, es estar todo el tiempo teniendo que aclarar que no soy eso que están nombrando" (Estudiante, trans, UNC).

Así mismo ello se traduce en los espacios institucionales (las aulas, el espacio administrativo y no docente, los espacios de salud y bienestar estudiantil) que demarcan un universo heteronormado y binario como el único posible, que no contempla necesidades específicas: "ni siquiera el ámbito de la universidad donde más o menos tenemos el privilegio de acceder a otro circuito de salud como más privilegiado que es el de bienestar estudiantil, aun así no hay profesionales formados para atender a personas trans digamos, no tienen perspectiva de género, no hay endocrinologue (sic) forma de para poder atendernos. Entonces es como que aun dentro de este ámbito bastante privilegiado, seguimos estando excluides (sic)". (Estudiante, trans, UNC)

Politizar las necesidades desde las propias experiencias situadas es una forma en que los feminismos han históricamente movilizado un conjunto de necesidades que parecían privadas o de orden de la intimidad. Desde estas lógicas de una política feminista, se puede contribuir a fomentar la erradicación de los sexismos y violencias patriarcales. 


\section{Prácticas y estrategias en la construcción de otros saberes: fisuras que permiten resistir y re-existir.}

A pesar de todo lo que venimos nombrando, podemos advertir que, tanto dentro como fuera del espacio áulico y universitario, se presentan otras lógicas de construcción y transmisión del saber, que demandan una ruptura epistemológica y academicista e incorporan nuevas estrategias de construcción del saber.

Los espacios que aparecen señalados como los más democráticos son seminarios y talleres optativos y electivos. Interpelan en la construcción de conocimiento y en la propuesta de una Universidad donde los feminismos hagan su presencia.

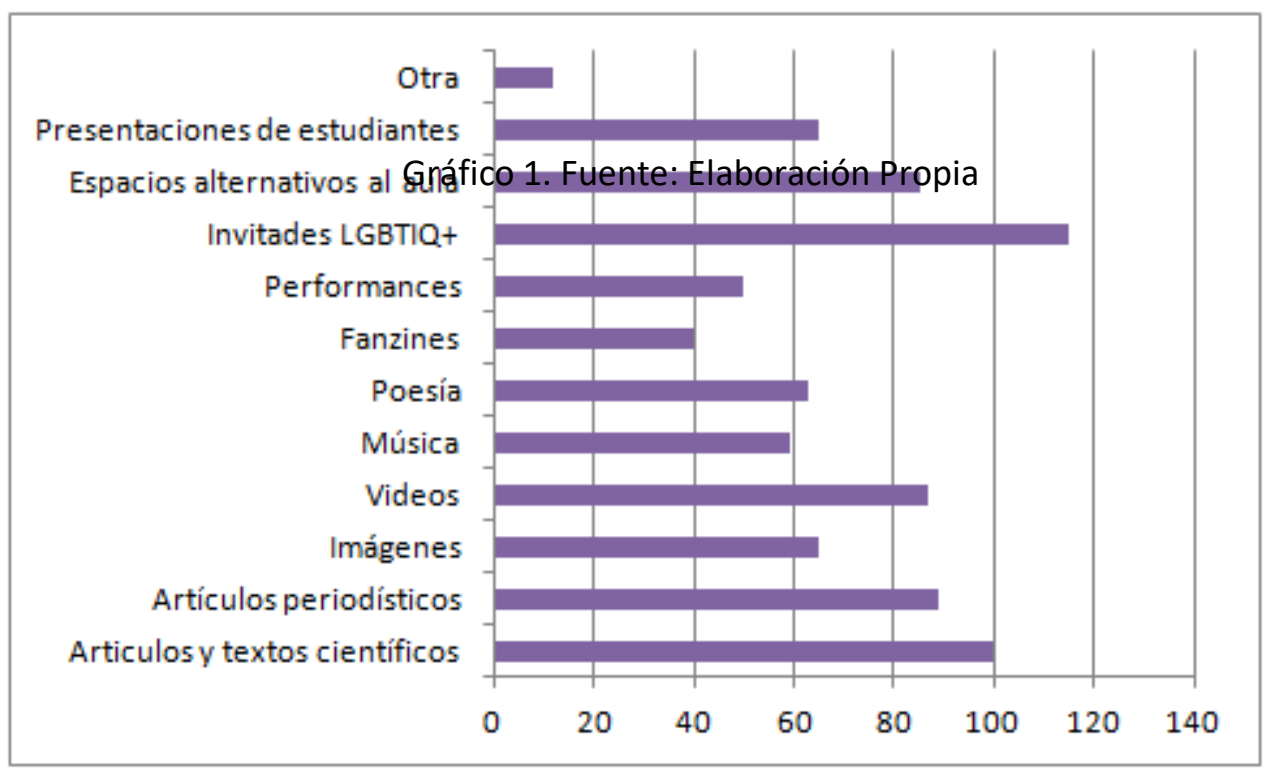

Figura 2: ¿Qué herramientas favorecerían una clase con perspectiva de género LGBTTTIQ+ y no binaria e inclusiva?. Fuente: Elaboración Propia. 
Como se puede observar del resultado de la encuesta, también surgieron los Cursos de extensión como promotores de miradas diversas, feministas y disidentes. Otro factor señalado en las encuestas es la presencia de docentes feministas que desde hace décadas vienen resistiendo al androcentrismo y sus prácticas y que han generado espacios institucionales que concentran investigaciones, estudios y activismos feministas en el marco de la Universidad. La creación de Áreas de investigación en género en Filosofía o en Ciencias Sociales, son muestras de una resistencia y reexistencia por parte de las históricas presencias feministas universitarias.

Así también, en la UNC existen políticas universitarias como aquella que reconoce el Derecho a la identidad y la expresividad de género $(2011)^{3}$ y el Plan de acciones que implementa la UNC para atender las violencias de género $(2015)^{4}$, las cuales han favorecido el tránsito estudiantil de mujeres y disidencias sexo-genéricas y que son producto de luchas y resistencias en el interior de los espacios institucionales. También el doctorado en Estudios de Género que, como espacio legitimado del saber, ha permitido institucionalizar los estudios de género y feministas en el marco de la Universidad. Estos son algunos de los ejemplos que nos muestran cómo se han venido filtrando los espacios feministas en el marco de la cisheteropatriarcal educación tradicional universitaria.

También podemos nombrar los logros obtenidos tras las luchas por la inclusión laboral trans. La facultad de filosofía, por ejemplo, ha implementado efectivamente espacios laborales para personas trans que actúan como una política positiva y ejemplar para el resto de la UNC. 
Por fuera del espacio áulico y universitario existen otras lógicas que desafían lo normado:

"En mi facultad, nosotros trabajamos en salud y trabajamos una concepción de salud contrahegemónica que es lo que prepondera nuestra facultad, un modelo hegemónico médico, nosotros intentamos trabajar lo contrario a ello y desarrollamos actividades académicas como módulos optativos, son nuestra estrategia fundamental" (C., Medicina)

Lo mismo ocurre con seminarios opcionales y de extensión que están de manera permanente en las carreras y que, si bien no tienen carácter de obligatoriedad, dan un cierto respiro a las lógicas patriarcales-clasistascoloniales del saber y permiten que el tránsito del estudiantado por la casa de estudios esté atravesado por bifurcaciones.

La recuperación de las trayectorias de formación militante y de participación en espacios colectivos permite al estudiantado valorar y visibilizar otras lógicas de construcción de saberes y otros lenguajes. No es que las y los estudiantes no se interesen por el saber académico, como reflejan los datos de la encuesta, donde el acceso a artículos científicos y textos académicos resulta un aspecto valorado. Sin embargo, es hora de revisar la jerarquía que ciertos saberes tienen por sobre aquellos que no han sido legitimados desde el conocimiento científico. Poder revisar estas jerarquías no cuestionadas permite revalorizar y encontrarse con estas otras formas de enseñanza-aprendizaje: espacios de educación popular, espacios artísticos y militantes y otros lenguajes y dispositivos visuales, orales, gráficos.

Así mismo revisar esta jerarquía supone repensar de qué manera estas voces y formatos pueden formar parte de estos proceso de formación, por ejemplo si nos preguntamos cómo hacer para que las voces, la oralidad irrumpa en las 
aulas más allá de la construcción de un panel. Este aspecto implica repensar desde las formas de accesibilidad al saber que históricamente han cuestionado los colectivos de personas con discapacidad y diversidad funcional, los saberes indígenas, no siempre sujetos a la lengua escrita, como así también los saberes de los colectivos trans y travesti que no siempre son conocimientos escritos.

Como se señala en el marco de las entrevistas realizadas, no sólo no es valorado, sino que existe una mirada crítica de estos colectivos respecto a la apropiación y el uso extractivista de la academia sobre estos saberes. Ello nos trae nuevas preguntas sobre cómo dialogar con los mismos sin violentar sus lógicas de construcción colectiva, su oralidad. ¿Acaso existen formas de traducción de ciertos saberes, desconocidos para algunos sectores, sin caer en un ejercicio de violencia?. Sin dejar de reconocer los esfuerzos que se vienen haciendo desde la universidad por parte de las feministas, nos preguntamos ¿cómo construir espacios que no sean de engañosa inclusión y traducción de estos otros/as para la Universidad, sino que tengan su propia voz?.

\section{A modo de cierre: ¿otra Universidad es posible?}

Recapitulando lo hasta aquí trabajado, es posible encontrar algunos caminos y propuestas posibles que nacen de lo que ya se está gestando y construyendo desde la institución que habitamos como actoras. Si bien diferentes unidades académicas están discutiendo los feminismos y los saberes LGBTTTIQ+ en sus aulas y asignaturas, aparecen demandas por cambios en los programas y planes de estudio para que incorporen las voces feministas y LGBTTTIQ+; así también se han puesto en funcionamiento diferentes espacios de atención a las 
violencias de género y laboral, y se disponen en la UNC diferentes dispositivos de inclusión.

Sin embargo, todavía hay voces que resisten y que transitan por los márgenes de la institución, aún se reproducen estos dispositivos extractivistas, cuando se desconoce que estas voces también tienen sus propias genealogías y memorias que no nacen necesariamente de las aulas.

Es por ello que, si nos preguntamos cuáles son los cambios y disrupciones que estas formas de construcción de pueden proponer desde estos márgenes y resistencias a la Universidad, precisamos identificar también, desde las memorias feministas y disidentes, cuáles son los caminos transitados desde la Universidad como por fuera de ella. Reconocer estas genealogías, resulta fundamental para no violentar la transmisión de estos saberes, para no apropiarnos de los mismos en traducciones académicas, sin embargo resulta una tarea urgente para transformar una sociedad heteropatriarcal encontrar un espacio en las formación y en la lógica de construcción de una institución como la Universidad.

De lo trabajado en esta investigación, nos llevamos al menos algunos aprendizajes que se convierten en una agenda posible. Creemos que es posible partir de reconocer otros saberes feministas, LGBTTTQI+, incorporarlos desde su autoría, no hablar por ellos/as/es, incluir otras lógicas de autoría colectiva y de producción; sumar otros soportes no académicos: orales, fanzines, poesía, videos, performances, espacios fuera de las aulas. También es importante recuperar lo recorrido, los caminos de las feministas que han ido haciendo historia en el marco universitario y que han concretado muchas de las políticas de acción positiva que aquí nombramos. Este cambio de mirada nos 
invita a repensar la escritura de la propuesta, los artículos, el lenguaje, los ejemplos, los relatos, las clases, y la formación de profesionales.

Todo ello supone como punto de partida poder mirarnos, reconocernos, con nuestras corporalidades y disidencias, como cuerpos sexuados, vinculadas/os y afectadas/os como actores sociales y políticos. El lenguaje no sexista, que disputa una institución como la Real Academia Española, es una demanda que en las Universidades argentinas ha podido instalarse desde estos recorridos pero frente al cual existen, aún, múltiples resistencias.

Los feminismos en sus diferentes tradiciones lo vienen señalando hace tiempo: lo personal es político, esta consigna dentro y fuera de las aulas.

\section{Bibliografía}

- Ahmed, S. (2015) La política cultural de las emociones. México DF: Universidad Nacional Autónoma de México, Programa Universitario de Estudios de Género.

- Bard Wigdor, G. y Artazo, G. (2016) "L@s Otr@s de la Universidad Pública: Exclusiones y Desafíos que Persisten en Argentina". Revista Latinoamericana de Educación Inclusiva, 10(2), 183-199. Recuperado de: https://scielo.conicyt.cl/pdf/rlei/v10n2/art12.pdf.

- Bonavitta, P., Becerra, J. C., de Garay Hernández, J., Johnson, C., Wigdor, G. B., Gastiazoro, M. E., Muñoz-Rodríguez, L. F., Artazo, G., Menoyo, S. \& Sarmiento, L. (2018). El género en la academia: los planes de estudio de la Universidad Nacional de Córdoba. Entorno, (66), 223236. 
- Bonilla Campos, A. (2014) Pertenencia, pertinencia y diferencia: discurrir por las fronteras del género, Quaderns de Psicologia , 2014, 16 (1), 1734.

- De Lauretis, T. (1996). La tecnología del género, Revista Mora, 2, 26 34.

- Donoso-Vázquez, T. y Velasco-Martínez, A. (2013) “¿Por qué una propuesta de formación en perspectiva de género en el ámbito universitario?" Revista Profesorado, 17 (1). Recuperado de: http://digibug.ugr.es/bitstream/10481/24906/1/rev171ART5.pdf

- Flores, V. (2018) Los cuerpos que (no) imaginamos. Lengua, poder y educación. Escritos Heréticos. Recuperado de: http://escritoshereticos.blogspot.com/2018/06/los-cuerpos-que-noimaginamos-lengua.html

- Maffía, D. (2007) Epistemología feminista: la subversión semiótica de las mujeres en la ciencia. Revista Venezolana de Estudios de la Mujer, 12(28), 63-98.

- OIT (2016) Las mujeres en el trabajo. Ginebra: Organización Internacional del Trabajo. Recuperado de: http://www.unesco.org/library/PDF/wcms_457094.pdf

- Rich, A. (2001) Sangre, pan y poesía. Prosa escogida 1979-1985. Barcelona: Icaria.

- Rovetto, F. y Figueroa, N. (2017) "Que la universidad se pinte de feminismos" para enfrentar las violencias sexistas. Descentrada. Revista interdisciplinaria de feminismos y género, 1(2): e026. Recuperado de: http://www.memoria.fahce.unlp.edu.ar/art revistas/pr.7919/pr.7919.pdf 
- Segato, R. (2008) Territorio, Soberanía y Crímenes de Segundo Estado: La Escritura en el Cuerpo de las Mujeres Asesinadas en Ciudad Juárez. Debate Feminista, 37.

- Troncoso Pérez, L., Follegati, L., \& Stutzin, V. (2019) Más allá de una educación no sexista: aportes de pedagogías feministas interseccionales, Pensamiento Educativo, 56(1).

- Valcárcel, A. (2008) Feminismo en el mundo global. Madrid: Cátedra.

- Viveros Vigoya, M. (2009) La sexualización de la raza y la racialización de la sexualidad en el contexto latinoamericano actual. Revista Latinoamericana de Estudios Familiares, 1(4), 63- 81. Recuperado de: http://www.derechoshumanos.un|p.edu.ar/assets/files/documentos/la-

\section{sexualizacion-de-la-raza-y-la-racializacion-de-la-sexualidad.pdf}

\section{Notas}

1 Mediante la ordenanza 9/11 del Consejo Superior de la UNC

2 Entendemos por sujetos feminizados a aquellos que se ocupan en posiciones de desventaja con respecto al sistema cisheteropatriarcal, capitalista y colonialista.

3 De acuerdo a la Ordenanza 9/11 del Consejo Superior de la UNC, se garantiza el derecho a la identidad de género y auto percibida en todo trámite administrativo, aún cuando no coincida con su nombre y sexo registrales.

4"Plan de Acciones y Herramientas para prevenir, atender y sancionar las Violencias de Género en el ámbito de la UNC" (Resolución Honorable Consejo Superior 1011/15) tiene como objetivo central la promoción en la comunidad universitaria de un ambiente libre de violencias de género y discriminación de cualquier tipo por razones de género y/o identidad sexual. 


\section{Agradecimientos:}

Agradecemos el trabajo del equipo compuesto por estudiantes, egresades y docentes que conforman el equipo de investigación que en la UNC, incluido en la Red de Investigación en diferenciales de género en la Educación Superior Iberoamericana de la Universidad de Alicante. 